\title{
Phototaxis in True Slime Mold Physarum polycephalum
}

\author{
Masakatsu Hato*, Tetsuo Ueda, Kenzo Kurihara and Yonosuke Kobatake \\ Faculty of Pharmaceutical Sciences, Hokkaido University, Sapporo, Japan
}

\begin{abstract}
Phototaxis of plasmodium of true slime mold Physarum polycephalum was studied as a function of light wavelength and intensity. The change in the motive force of protoplasmic streaming $\left(\bar{\Delta}_{\mathrm{t}}\right)$ or isometric tension $\left(\overline{\Delta F} / \bar{F}_{\mathrm{o}}\right)$ was taken as the phototactic response. Three active spectral regions exist in the action spectrum of phototaxis. The blue light region $\left(\lambda_{\max }=490 \mathrm{~nm}\right)$ or far-red light region $\left(\lambda_{\max }=720 \mathrm{~nm}\right)$ induced negative taxis, and the red light region $\left(\lambda_{\max }=650 \mathrm{~nm}\right)$ led to positive taxis. The absorption spectrum of plasmodial yellow pigments did not coincide with the maxima of the action spectrum. The time course of the phototactic response $\overline{\Delta P}_{t}$ was independent of intensity for a given wavelength so far as the intensity of stimulating light exceeded the threshold value, suggesting that light stimulation acted as a trigger for initiating the tactic movement. The mode of phototaxis resembled that of chemotaxis for motive force, i.e., the steady value of phototactic motive force $\Delta \mathrm{P}$ changed from zero to $8-12 \mathrm{~cm} \mathrm{H}_{2} \mathrm{O}$ in rather narrow intensity regions, and $\Delta \mathrm{P}$ values were independent of the intensity of light so far as the intensity exceeded the threshold value $I_{c}$. When the slime mold was illuminated with blue $(500 \mathrm{~nm}, 510 \mathrm{~nm})$ and far-red $(720 \mathrm{~nm})$ light, isometric tension increased with the intensity of light $\left(I>I_{c}\right)$ while for red light $(650 \mathrm{~nm})$ isometric tension did not show an appreciable change on illumination.
\end{abstract}

The behaviour of living organisms is affected by various kinds of external stimuli, such as light, chemical compounds and temperature. This is also true in the case of myxomycetes. According to observations by Krzemieniewska (12) slime mold plasmodia in vigorous vegetative state are usually found in dark wet places. In this state, light exerts a distinct inhibitory effects on vegetative growth (15). On the other hand, plasmodia in the pre-sporangial state migrate from dark toward light dry areas; thus sporangia are usually found in light areas. For myxomycete Physarum nudum, Rakoczy (15) found that light but not humidity was an essential factor for a change in habitat. This suggests that phototaxis plays an important role in finding suitable places for growth and sporulation. However, no quantitative study on phototaxis has been reported.

The plasmodium is a large protoplasm having neither cell boundary nor cell wall. Changes in physical properties, such as motive force of protoplasmic streaming or isometric tension can be used as measures of light response. Hence, the plasmodium is an organism suitable for studying the mechanism of phototaxis.

*Present address: Research Institute for Polymers and Textiles, Sawatari, Kanagawa-ku Yokohama, Japan. 
There are several problems on the effects of light on the slime mold Physarum polycephalum: the nature of photoreceptor molecules, the correlation between phototaxis and sporulation, and comparisons of responses induced by light and chemical stimuli. The present study examines the phototactic responses of the slime mold Physarum polycephalum in the vegetative state by measuring the changes in the motive force of protoplasmic streaming and in the isometric tension, as a function of wavelength and intensity of stimulating light.

\section{MATERIALS AND METHODS}

Materials. The slime mold Physarum polycephalum was kindly furnished by Prof. N. Kamiya of Osaka University. It was cultured by the method described by Camp (1), i.e., cultured with oatmeal on wet filter paper in a dark place at $20^{\circ} \mathrm{C}$. Young plasmodium was left overnight on a $0.8 \%$ agar gel without feeding. By this treatment, plasmodium differentiated into "tip" and "strand" portions. These portions were used for experiments. The slime mold was habituated in a dark place for more than $1 \mathrm{~h}$ before the experiments.

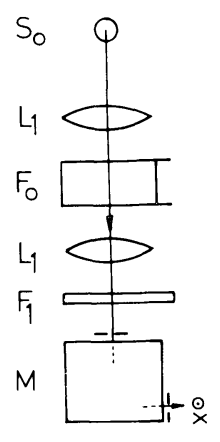

a

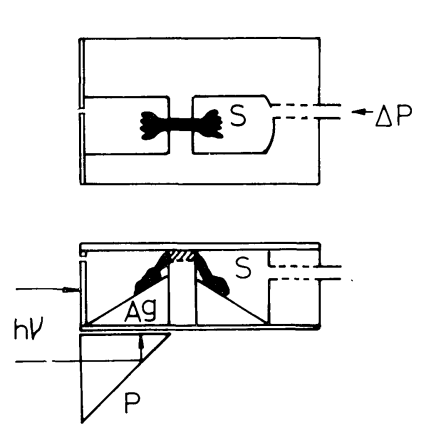

b

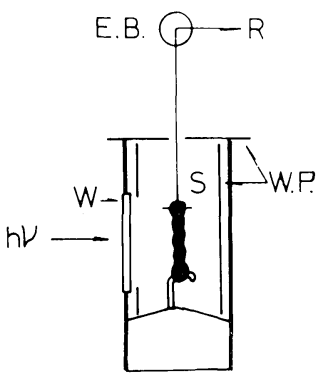

C

Fig. 1a. Schematic illustration of the optic system for the stimulating beam. At position $\mathrm{X}$ a double chamber cell or moist chamber was placed for measurements of tactic motive force or isometric tension, respectively. $\mathrm{S}_{0}$, light source of $1 \mathrm{KW}$ incandescent projector lamp; $\mathrm{L}_{1}$, lens; $\mathrm{F}_{1}$, filter for adjusting light intensity; M, monochrometer.

Fig. 1b. Modified double chamber cell for measuring the phototactic motive force. S, slime mold; Ag, $1 \%$ agar gel; $\mathrm{P}$, a prism,

Fig. 1c. Moist chamber for measuring isometric tension. E.B., electrobalance made from a conventional milli-ammeter; R, strip chart recorder; S, slime mold; W.P., wet filter paper.

Light source and optics. A schematic diagram of the optics is shown in Fig. 1a. Photographic films exposed at different times were used as filters for adjusting light intensity, and the monochrometer used was from the Farrand spectrofluorometer (model 104243-B, for 400nm$650 \mathrm{~nm}$ ) and Hitachi recording spectrophotometer (ESP-2U, for $500 \mathrm{~nm}-800 \mathrm{~nm}$ ). The monochrometer was calibrated by using a He-Ne laser. The intensity of monochromatic light was determined by a photodiode (SPD-551, Sharp Electric Co., Osaka, Japan) which was calibrated by using a Spectro Irradiator (Japan Spectro Scopic Co., Tokyo). At $\lambda=546 \mathrm{~nm}$, the Reinecke's salt actinometer was also used in calibration (20). 
A tungsten $8 \mathrm{~V}-30 \mathrm{~W}$ microscope lamp (Olympus Co., Tokyo) was used to observe protoplasmic streaming. To protect the slime mold from phototactically active light, a glass filter (Corning 3387) and a solution filter $\left(10 \%\right.$ aqueous solution of $\mathrm{CuSO}_{4} 5 \mathrm{H}_{2} \mathrm{O}$ and $6 \%$ aqueous solution of $\mathrm{CoSO}_{4} 7 \mathrm{H}_{2} \mathrm{O}$ ) were inserted between the microscope lamp and the slime mold $\left(\lambda_{\max }=580 \mathrm{~nm}, 50 \%\right.$ cut off; $540 \mathrm{~nm}$ and $\left.610 \mathrm{~nm}\right)$. As will be shown later in the text, yellow light is phototactically inactive.

Determination of motive force of protoplasmic streaming. The motive force of protoplasmic streaming was determined with the aid of the double chamber method originated by Kamiya (10). A schematic diagram of the double chamber cell modified for phototaxis measurements is shown in Fig. 1b. Stimulating light enters the left chamber (hereafter referred to as the stimulating chamber) partly through the side window made of slide glass and partly from the bottom of the stimulating chamber through a prism $\mathbf{P}$, forming a light spot with a diameter of ca. $5 \mathrm{~mm}$. The other chamber (called reference chamber) was kept dark throughout the experiments. The double chamber cell was painted black to avoid stray light. Both chambers were filled with moist air.

A curve representing autonomous change in the motive force (dynamoplasmogram) was obtained by producing a pressure difference between two chambers just to stop protoplasmic streaming in the strand portion. The applied difference in pressure was measured by a manometer filled with water. The average values of the pressure $\bar{P}_{t}$ (for one cycle of oscillation) were determined by a line which divided the waves equally into an upper and lower part, i.e., polarity-line (10). When the polarity-line was practically constant for ca. $15 \mathrm{~min}$, the average value of $\overline{\mathrm{P}}_{t}$ over the time interval was taken as the steady value $\overline{\mathrm{P}}_{\mathrm{o}}$. The difference in the average pressure with and without illumination $\overline{\mathrm{P}}^{*}-\overline{\mathrm{P}}_{\mathrm{o}}(=\Delta \mathrm{P})$ was referred as the motive force of the phototactic movement of the slime mold (18). When the initial and final values of $\overline{\mathrm{P}}_{\mathrm{o}}$ were different (up to ca. $2 \mathrm{~cm} \mathrm{H}_{2} \mathrm{O}$ ), the average value was taken as $\overline{\mathrm{P}}_{\mathrm{o}}$. In cases where the difference was more than $4 \mathrm{~cm} \mathrm{H}_{2} \mathrm{O}$ or when the change was irreversible, the results were not included in the data. Positive value of $\Delta \mathrm{P}$ was defined for positive phototaxis or vice versa.

Determination of isometric tension. Isometric tension was measured by a method similar to that proposed by Kamiya, Allen and Zeh (11). The strand portion of the slime mold was hung down in the moist chamber as illustrated in Fig. 1c. The change in isometric tension $F$ was detected by an electro-balance (E.B.) and recorded by a strip chart recorder (R). More detailed descriptions of the measurements of isometric tension will be published elsewhere (19). Stimulating light beam enters the chamber through the glass window (W) forming a light spot $(5 \times 2 \mathrm{~mm})$ on the strand (S). The diameter of the strand used ranged from $300 \mu \mathrm{m}$ to $500 \mu \mathrm{m}$ and changes in the diameter within this range did not affect the experimental results. All experiments were carried out at $20-22^{\circ} \mathrm{C}$.

\section{RESULTS}

Effects of light on the motive force of protoplasmic streaming. Fig. 2 shows typical examples of the dynamoplasmogram with or without light illumination of desired wavelength and intensity. Fig. 2a shows a case where the slime mold was exposed to blue light of $500 \mathrm{~nm}$, which indicates that the motive force shifts toward the reference chamber side by ca. $10 \mathrm{~cm} \mathrm{H}_{2} \mathrm{O}$. The slime mold showed a negative phototaxis in this spectral region. It was noted that the motive force had a constant value after 10-15 min of illumination and further illumination led to no appreciable change in the phototactic motive force, $\overline{\Delta P}_{\mathrm{t}}$, and these values were taken as steady values and denoted by $\overline{\Delta P}$. A part of the blob of Physarum in the stimulating chamber moved out of the light spot after prolong illumination. The illumination time was then limited to within 


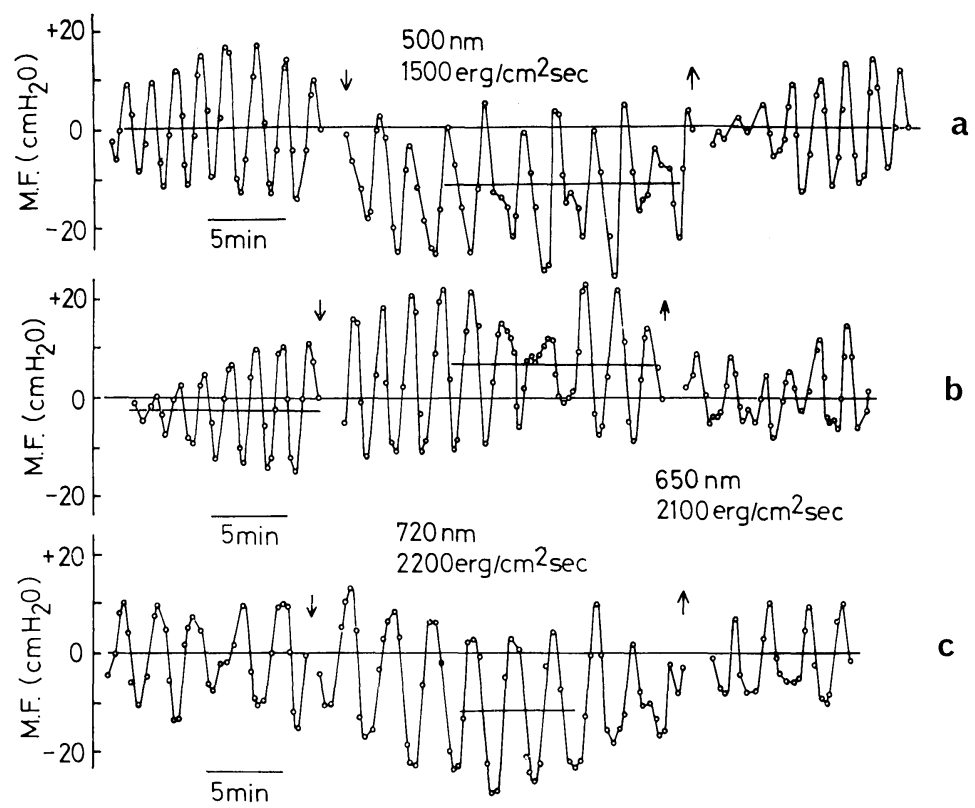

Fig. 2. Dynamoplasmograms which show negative phototaxis of plasmodium in response to blue (500nm, Fig. 2a) and far-red (720nm, Fig. 2c) light. Fig. 2b shows positive phototaxis in response to red light $(650 \mathrm{~nm})$. All experiments were carried out in moist air. Horizontal lines in the figures show $\overline{\mathbf{P}}$ and $\overline{\mathbf{P}^{*}}$; ordinate, motive force of protoplasmic streaming (M.F.) in $\mathrm{cm} \mathrm{H}_{2} \mathrm{O} ; \downarrow$, light stimuli applied; $\uparrow$, light stimuli removed.

20-30 min. When the light stimuli were removed, tactic motive force ${\overline{\Delta \mathrm{P}_{t}}}_{\mathrm{t}}$ returned gradually to the initial zero level. Fig. $2 \mathrm{~b}$ and $2 \mathrm{c}$ show typical results of illumination with red $(650 \mathrm{~nm})$ and far-red light $(720 \mathrm{~nm})$, respectively. It is clear from Fig. $2 b$ that the motive force shifted toward the illuminated chamber side by ca. $9 \mathrm{~cm} \mathrm{H}_{2} \mathrm{O}$ in $\overline{\Delta \mathrm{P}}$, i.e., the slime mold showed positive phototaxis. On the other hand, as seen in Fig. 2c, illumination with far-red light $(720 \mathrm{~nm})$ induced negative phototaxis. It is noted that negative phototaxis induced by far-red light was transient, i.e., $\overline{\Delta \mathbf{P}}_{\mathrm{t}}$ value attained ca. $-10 \mathrm{~cm} \mathrm{H}_{2} \mathrm{O}$ after $10-15 \mathrm{~min}$ of illumination and then began returning toward the initial zero value.

The time course of the change in the tactic motive force $\overline{\Delta \mathbf{P}_{t}}$ in response to red or far-red light (Fig. 3-a) and to blue light (Fig. 3-b) is shown with light stimuli applied at time zero. $\overline{\Delta \mathrm{P}_{\mathrm{t}}}$ values were determined from the difference in polarity-lines at each half cycle. As seen in Fig. 3 the tactic motive force $\overline{\Delta \mathbf{P}}_{\mathrm{t}}$ attained steady values $(|\Delta \mathrm{P}|=$ 8-12 $\mathrm{cm} \mathrm{H}_{2} \mathrm{O}$ ) after $10-15 \mathrm{~min}$ of illumination with wavelengths of $650 \mathrm{~nm}, 510 \mathrm{~nm}$ $500 \mathrm{~nm}$ and $480 \mathrm{~nm}$. At wavelength of $720 \mathrm{~nm}, \overline{\Delta \mathrm{P}}_{\mathrm{t}}$ reached the minimum value of -10 to $-12 \mathrm{~cm} \mathrm{H}_{2} \mathrm{O}$, and then approached zero. These time courses were independent of the intensities of light illuminated so far as intensity exceeded the respective threshold value $I_{c}$. For example, a tenfold increase in the intensity of red light $(650 \mathrm{~nm}$, from $320 \mathrm{erg} / \mathrm{cm}^{2}$. sec to $3200 \mathrm{erg} / \mathrm{cm} .{ }^{2} \mathrm{sec}$ ) caused no appreciable difference in the time course of the response curve. These results indicate that light acts as a trigger in initiating the tactic movement, but not as an energy source for the movement.

Fig. 4 represents the steady values of phototactic motive force $\overline{\Delta \mathrm{P}}$ as a function of intensity at various wavelengths. At $720 \mathrm{~nm}$, the minimum values of $\overline{\Delta \mathrm{P}}_{\mathrm{t}}$ were plotted. 


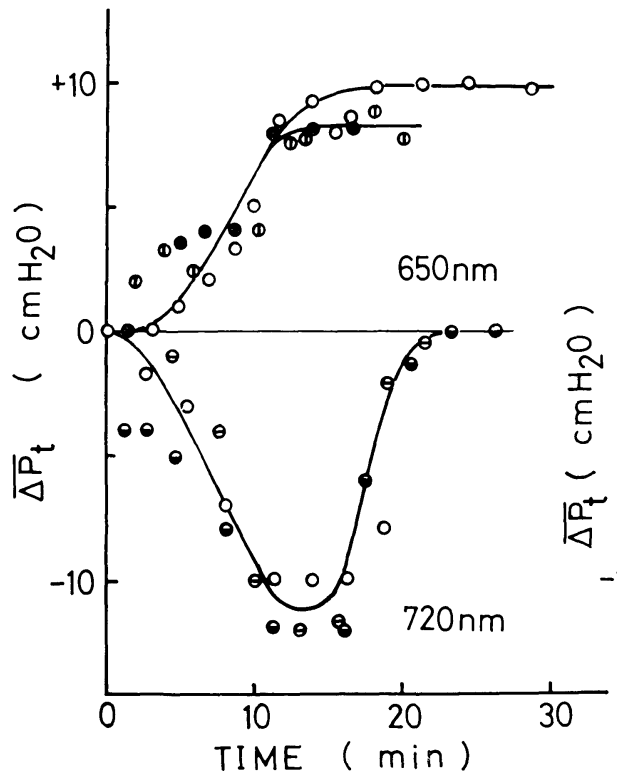

a

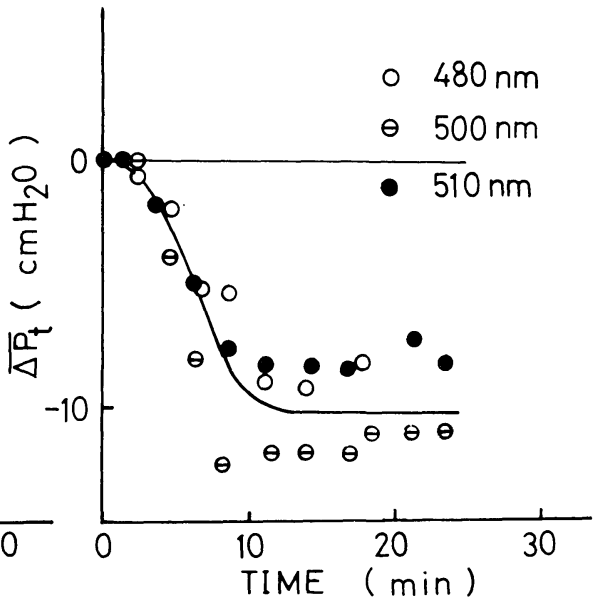

b

Fig. 3. Time course of tactic motive force $\overline{\Delta P}_{t}$ in response to light stimuli. Fig. 3a. Abscissa, time in minutes; ordinate, phototactic motive force $\bar{\Delta} \mathrm{P}_{\mathrm{t}}\left(\right.$ in $\left.\mathrm{cm} \mathrm{H}_{2} \mathrm{O}\right)$. For $650 \mathrm{~nm}:-, I=320 \mathrm{erg} /$ $\mathrm{cm}^{2}$. sec; $\bigcirc, I=2,100 \mathrm{erg} / \mathrm{cm}^{2}$. $\mathrm{sec} ; \emptyset, I=3,200 \mathrm{erg} / \mathrm{cm}^{2}$. $\mathrm{sec} ;$ for $720 \mathrm{~nm}: \ominus, I=780 \mathrm{erg} / \mathrm{cm}^{2}$. $\mathrm{sec} ; \bigcirc$, $I=22,00 \mathrm{erg} / \mathrm{cm}^{2}$. sec; $\ominus, I=6,000 \mathrm{erg} / \mathrm{cm}^{2}$. sec. Fig. 3b. Abscissa, time in minutes; ordinate, phototactic motive force (in $\mathrm{cm} \mathrm{H}_{2} \mathrm{O}$ ). For $480 \mathrm{~nm}: \bigcirc, I=6,800 \mathrm{erg} / \mathrm{cm}^{2}$. $\mathrm{sec}$; for $500 \mathrm{~nm}: \ominus, \mathrm{I}=1,500 \mathrm{erg}$ / $\mathrm{cm}^{2}$. sec; for $510 \mathrm{~nm}$ : $, \mathrm{I}=30,000 \mathrm{erg} / \mathrm{cm}^{2}$. sec.

a

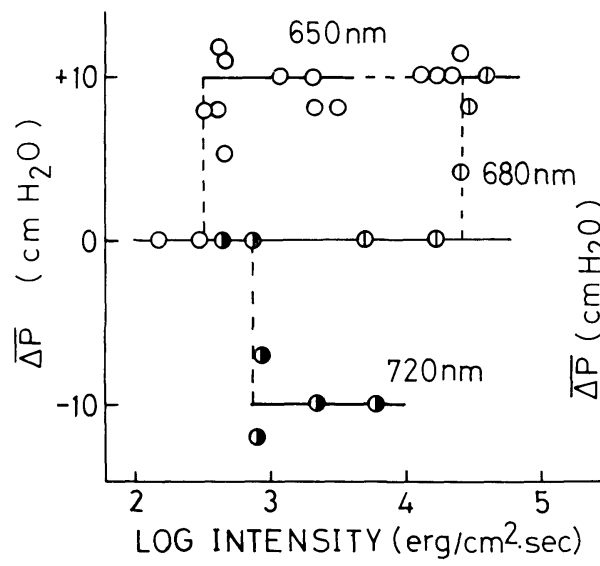

b

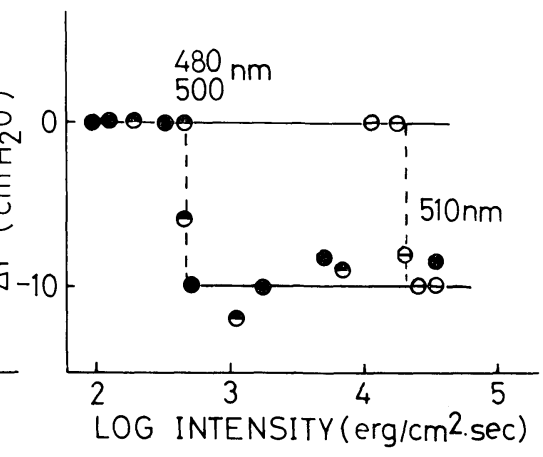

Fig. 4. Phototactic motive force $\overline{\Delta \mathrm{P}}$ as a function of intensity of stimulating light at various wavelengths. Fig. 4a. Abscissa, log intensity $\left(\mathrm{erg} / \mathrm{cm}^{2}\right.$. sec); ordinate, phototactic motive force $\overline{\Delta P}$ (in $\mathrm{cm} \mathrm{H}_{2} \mathrm{O}$ )., $500 \mathrm{~nm}$; $\odot, 480 \mathrm{~nm}$. 
The figure shows the results obtained by illumination of red $(650 \mathrm{~nm}, 680 \mathrm{~nm})$, far-red $(720 \mathrm{~nm})$ and blue $(480 \mathrm{~nm}, 510 \mathrm{~nm})$ light. It appears that at each wavelength the tactic motive force $\overline{\Delta \mathrm{P}}$ changed from zero to a certain maximum and minimum value $\left(|\overrightarrow{\Delta \mathrm{P}}|=8-10 \mathrm{~cm} \mathrm{H}_{2} \mathrm{O}\right)$ in a rather narrow intensity range; the $\overline{\Delta \mathrm{P}}$ value appeared to change in a nearly all-or-nothing fashion. We denoted the lowest values of light intensity that induced phototaxis by $\mathbf{I}_{c}$. If the light intensity of a fixed wavelength was below $I_{c}$, illumination of at least $20-30 \mathrm{~min}$ induced no appreciable taxis. Once intensity exceeded $\mathrm{I}_{c}$, the tactic motive force $\overline{\Delta \mathrm{P}}$ became ca. $\pm 10 \mathrm{~cm} \mathrm{H}_{2} \mathrm{O}$ after 10-15 min of exposure and the tactic motive force $\overline{\Delta \mathrm{P}}$ remained constant with increased light intensity. The values of $I_{c}$ depended upon the wavelength, i.e., 500 $\mathrm{erg} / \mathrm{cm}^{2} . \mathrm{sec}$ for $500 \mathrm{~nm}$ and $480 \mathrm{~nm}, 20,000 \mathrm{erg} / \mathrm{cm}^{2}$. sec for $510 \mathrm{~nm}, 300 \mathrm{erg} / \mathrm{cm}^{2}$. sec for $650 \mathrm{~nm}, 25,000 \mathrm{erg} / \mathrm{cm}^{2} . \mathrm{sec}$ for $680 \mathrm{~nm}$ and $700 \mathrm{erg} / \mathrm{cm}^{2} . \mathrm{sec}$ for $720 \mathrm{~nm}$. For yellowgreen $(520 \mathrm{~nm}-630 \mathrm{~nm})$ and near ultraviolet light $(400 \mathrm{~nm}-450 \mathrm{~nm})$, the slime mold showed no phototaxis $(\overline{\Delta \mathrm{P}}=\mathrm{O})$ even at the highest intensity used in the study, i.e., $10^{4} \mathrm{erg} / \mathrm{cm}^{2} . \mathrm{sec}$
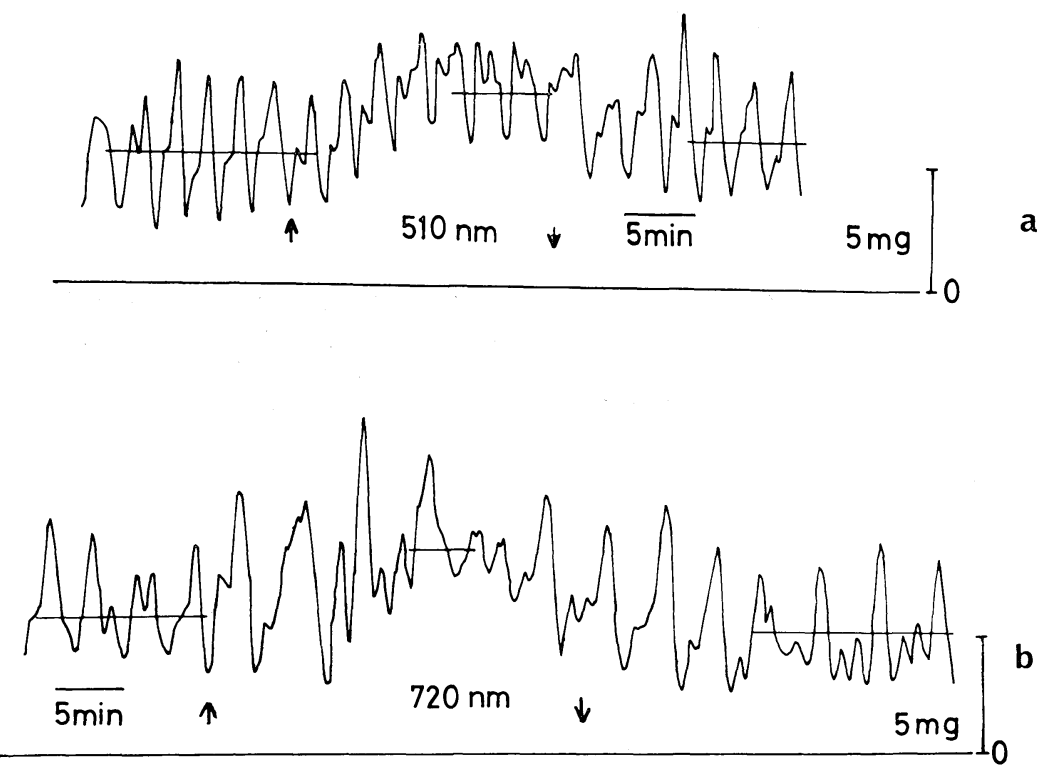

Fig. 5. Changes in isometric tension in response to blue $\left(510 \mathrm{~nm}, 90,000 \mathrm{erg} / \mathrm{cm}^{2} . \mathrm{sec}\right)$ and far-red light $\left(720 \mathrm{~nm}, 2,500 \mathrm{erg} / \mathrm{cm}^{2} . \mathrm{sec}\right)$ light. Horizontal lines in the figure show $\bar{F}_{\mathrm{o}}$ and $\mathrm{F}^{*}$. $\uparrow$, Light stimuli applied; $\downarrow$, light stimuli removed.

Effects of light on isometric tension of the slime mold. Fig. 5 shows the typical response curve of the isometric tension when a plasmodial strand was illuminated by a light beam of a given wavelength. Characteristic rhythmical oscillations were observed (period of 1.5-3 minutes, amplitude of 2-5 mg). The average oscillation values were determined by the same method as that used in the determination of $\overline{\mathbf{P}}_{\mathrm{t}}$ and $\overline{\Delta \mathrm{P}}$. If the moist chamber was kept dark (control) the average oscillation value remained at a constant level $F_{o}$. On illumination with blue light $(510 \mathrm{~nm})$, the tension began to increase gradually and approached a constant level $\mathrm{F}^{*}$ after $10-15$ min of illumination 


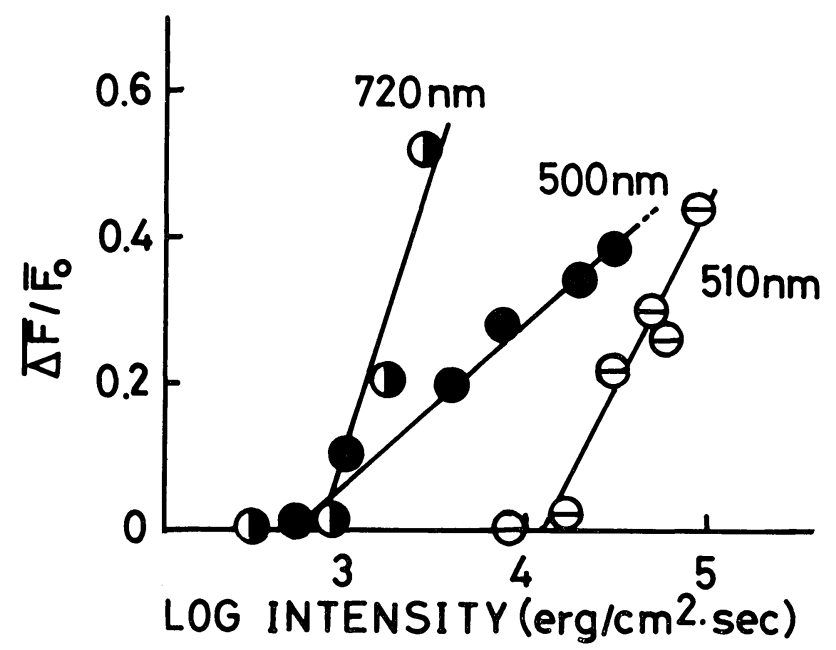

Fig. 6. Changes in isometric tension as a function of intensity of stimulating light of various wavelengths. Abscissa, $\log$ intensity $\left(\mathrm{erg} / \mathrm{cm}^{2}\right.$. sec); ordinate, change in isometric tension $\overline{\Delta \mathrm{F}} / \mathrm{F}_{\mathrm{o}}$.

(Fig. 5a). Further illumination led to no appreciable increase in tension, $\overline{\mathrm{F}^{*}}$. The amplitude as well as the period of oscillation changed from sample to sample on illumination. Under illumination, the strand of slime mold moved away from the light spot and showed a twisting motion, changing the shape appreciably. Thus, the illumination time was limited within 20-30 min. When light stimuli were removed, the tension began to decrease toward the initial level $\bar{F}_{\mathrm{o}}$. The values of $\Delta \mathrm{F} / \bar{F}_{\mathrm{o}}=\left(\overline{\mathrm{F}}^{*}-\overline{\mathrm{F}}_{\mathrm{o}}\right) / \mathrm{F}_{\mathrm{o}}$ were taken as phototactic responses of the isometric tension. When the initial and final $\bar{F}_{o}$ were different, the average value of the two was used as $\bar{F}_{\mathrm{o}}$. The effects of illumination with far-red light $(720 \mathrm{~nm})$ are shown in Fig. 5b. In this case, the change in tension was transient as observed in the response curve of the motive force (Figs. 2c and 3a). At $650 \mathrm{~nm}$, the tension did not increase but seemed to decrease, but the change was so small that it was difficult to conclude that this was really due to the light stimulus. Fig. 6 shows the $\overline{\Delta F} / \mathrm{F}_{\mathrm{o}}=\left(\mathrm{F}^{*}-\mathrm{F}_{\mathrm{o}}\right) / \mathrm{F}_{\mathrm{o}}$ values obtained with various wavelength as a function of light intensity. Fig. 6 shows that the logarithmic relationship (Weber-Fechner law) holds over a rather wide range of intensity when the light intensity exceeded the respective threshold value $I_{c}$. It was noted that the $I_{c}$ values determined from measurements of isometric tension coincided closely with the values determined from the tactic motive force (Fig. 4).

Action spectrum for phototaxis of slime mold P. polycephalum. Fig. 7 shows the action spectrum for phototaxis of the slime mold. For comparison, the absorption spectrum of the plasmodial yellow pigment(s) extracted with methyl alcohol is shown. The absorption maximum of the extracted pigment(s) was around $370 \mathrm{~nm}-400 \mathrm{~nm}$ which agrees with the values of intact cells. As seen from the figure, there were three active spectral regions: one (red light) for positive and two (blue and far-red light) for negative phototaxis. The relative effectiveness of the blue and red light was approximately equal, whereas that of far-red light was ca. $40-50 \%$ of the former two. The slime mold exhibited positive taxis only to light in very narrow spectral regions. Hence, the reason for plasmodium moving away from white light may be due to the wider spectral regions available for negative phototaxis. 


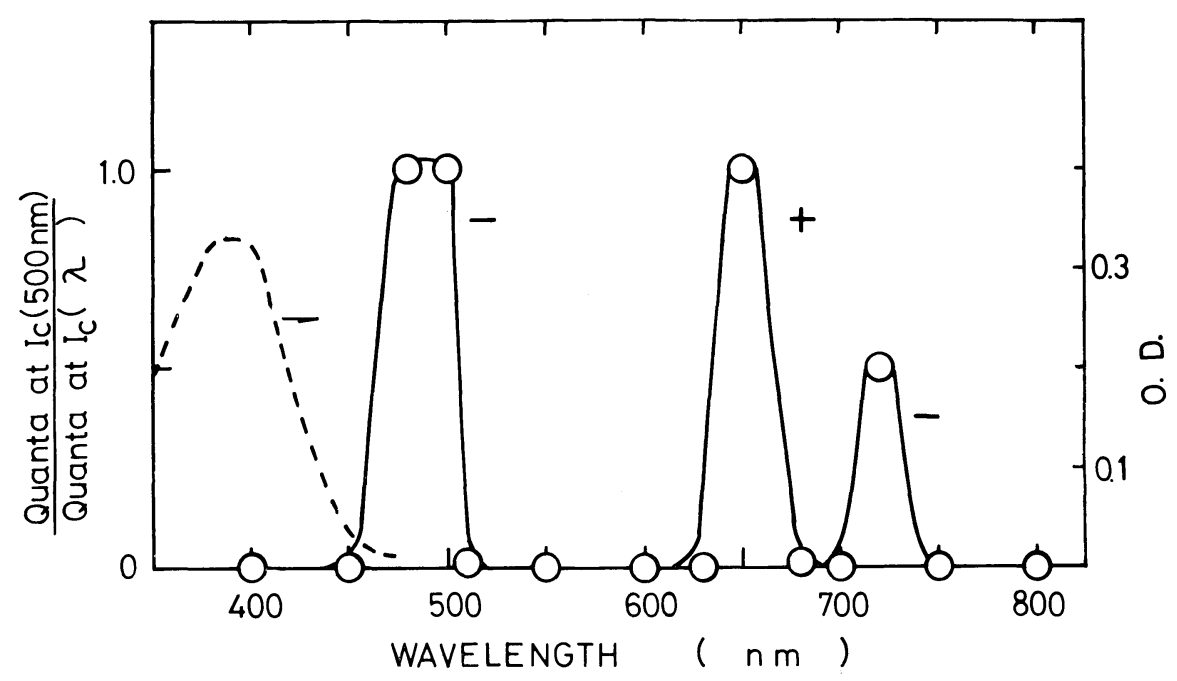

Fig. 7. Action spectrum for phototaxis of plasmodium Physarum polycephalum. Abscissa, wavelength $(\mathrm{nm})$; left ordinate, relative effectiveness of light on phototaxis evaluated by the reciprocal of the number of photons at the threshold intensity, $I_{c}$, Quanta at $I_{c}(500 \mathrm{~nm}) /$ Quanta at $I_{c}(\lambda)$; right ordinate, optical density (O.D.). +, positive phototaxis; - , negative phototaxis; dotted lines, absorption spectrum of plasmodial yellow pigment(s) extracted with methyl alcohol.

\section{DISCUSSION}

Photoreceptor molecules. The action spectrum for phototaxis of the slime mold $P$. polycephalum suggests that there are at least two different photoreceptors. It is generally believed that the action spectra for negative and positive (topo)-phototaxis are identical, as demonstrated by Halldal (7) for Volvocales (Platymonas, Dunaliella, and Stephanoptera). A few exceptions have been found in certain cultures of Chlamydomonas reinhardi, where negative and positive phototaxis take place in different spectral regions $(4,9)$. But the photoreceptor molecules in such cases have not yet been identified. In this respect, it may be interesting to estimate the photoreceptor molecules of the slime mold $P$. polycephalum.

As seen in Fig. 7, the action spectrum does not agree with the absorption spectrum of plasmodial yellow pigment(s). Thus, the yellow pigment(s) were not considered as photoreceptor molecules. The figure shows the opposite effect in the red and far-red spectral regions, i.e., red light $(650 \mathrm{~nm})$ induced positive taxis, whereas far-red light $(720 \mathrm{~nm})$ induced negative taxis. The antagonistic effects in these spectral regions are well known in plant photomorphogenesis. It is widely accepted that the chromoprotein known as phytochrome is responsible for the red-far-red antagonism. Note that the action spectrum obtained from phototaxis of $P$. polycephalum closely resembles the absorption spectra of phytochromes, especially the phytochromes of alga Mesotaenium and liverwort Sphaerocarpos (17). Considering these results together with the antagonistic effects of red and far-red light on sporulation (14) (described later), it is quite possible that phytochrome (at least molecules similar to phytochrome) is responsible for the regulation of phototaxis in the red and far-red spectral regions.

It is well known that blue light is effective in phototaxis of flagellated algae, such as Euglena and Volvox (3), photomorphogenesis (e.g., inhibition of sporulation in 
Alternaria solani (13)) and phototropism of Avena (16). Many investigators have suggested that the photoreceptor(s) for blue light is flavin chromophore (or carotenoid). Gray (5) found that a considerable amount of riboflavin is synthesized in the culture of $P$. polycephalum maintained by the Camp method (1). $P$. polycephalum has a deep yellow color with an absorption maximum of $380 \mathrm{~nm}$, hence the decline of the action spectrum below 470nm may be due to the masking effect of the deep yellow pigment(s). Therefore, the flavin chromophore may be involved in absorbing blue light, although it is premature to definitely come to this conclusion.

Comparison of the action spectrum of phototaxis with sporulation. Several studies have reported the effect of light wavelength on sporulation of Physarum polycephalum. Nair and Zabka (14) studied the effects of red and far-red light on sporulation in $P$. polycephalum and found that light in the red range $(650 \mathrm{~nm}-700 \mathrm{~nm})$ induced sporulation, whereas far-red light $(690 \mathrm{~nm}-750 \mathrm{~nm})$ did not. The observation that $P$. polycephalum did not form sporangia in whole red light $(650 \mathrm{~nm}-750 \mathrm{~nm})$ suggests the antagonistic effect of red and far-red light (14). Considering these observations together with the present results, it is inferred that phytochrome acts as a common photoreceptor molecule for phototaxis and sporulation. Gray (6) and later Daniel and Rush (2) found that blue light $(350 \mathrm{~nm}-580 \mathrm{~nm})$ was effective (the shorter the wavelength, the more effective) in inducing sporulation. Blue light $(400 \mathrm{~nm}-470 \mathrm{~nm})$ was ineffective for inducing phototaxis, as seen Fig. 7. Therefore, the photoreceptor for sporulation in response to blue light seems to be different from that for phototaxis.

Comparison between phototactic and chemotactic responses. It is interesting to compare the mode of tactic responses induced by light and chemical stimuli. This may give us information on the nature of the transductive system in plasmodium. In a previous paper (18) dealing with chemotaxis of the slime mold $P$. polycephalum, we reported that each chemical has its respective threshold concentration for induction of tactic movement, and once the concentration exceeds the threshold, the tactic motive force changes from zero to ca. $\pm 10 \mathrm{~cm} \mathrm{H}_{2} \mathrm{O}$ in a rather narrow concentration range. Similar results have been obtained for phototaxis (Fig. 4). Moreover, the time course of chemotactic and phototactic movements resembled each other, i.e., the average motive force $\overline{\Delta \mathbf{P}}_{\mathrm{t}}$ reached steady values in $10-15 \mathrm{~min}$ after stimulation by light and chemicals. This indicates that the phototactic and chemotactic movements are essentially the same so far as the generation of tactic motive force is concerned, although the receptor sites or molecules are considered to be entirely different from each other. On the other hand, several differences were observed in isometric tension. In chemotaxis, repellants or attractants led to an increase or decrease, respectively, of amplitude of tension. The baseline of tension did not change appreciably. Illumination with blue and far-red light which induced negative phototaxis increased the baseline of the tension (Fig. 5). The amplitude of the tension changed from sample to sample. Illumination with red light which induced positive phototaxis did not change tension appreciably. Considering these results it seems difficult at present to find a simple relationship between the phototactic motive force and the change in isometric tension.

Acknowledgments. One of the authors (M.H.) is deeply indebted to the Science and Technology Agency and Dr. Mitsuo Suzuki, Research Institute for Polymers and Textiles, for giving him an opportunity to work on this project and for continuous interest and encouragement. 


\section{REFERENCES}

1. Camp, W.G. A method of cultivating myxomycete plasmodia. Bull. Torrey Bot. Club. 63, 141164,1936

2. DANIEL, J.W. and H.P. Rush. Method for inducing sporulation of pure cultures of the myxomycete Physarum polycephalum. J. Bacteriol. 82, 234-240, 1962

3. Feinleib, M.E. and G.M. CURRY. The nature of the photoreceptor in phototaxis. In Handbook of Sensory Physiology, Vol. 1, ed. W.R. Loewenstern, Springer-Verlag, Berlin, pp. 366-395, 1971

4. FeINLEIB, M.E. and G.M. Curry. Methods for measuring phototaxis of cell populations and individual cells. Physiol. Plant. 20, 1083-1095, 1967

5. GraY, W.D. Riboflavin synthesis in cultures of Physarum polycephalum. Ohio J. Sci. 55, 212214,1955

6. GrAY, W.D. Further studies on the fruiting Physarum polycephalum. Mycologia 45, 817-824, 1953

7. Halldal, P. Action spectra of phototaxis and related problems in Volvocales, Ulva-Gametes and Dinophycease. Physiol. Plant. 11, 118-153, 1958

8. Halldal, P. Ultraviolet action spectra of positive and negative phototaxis in Platymonas subcordiformis. Physiol. Plant. 14, 133-139, 1961

9. Halldal, P. Action spectra of induced phototactic response change in Platymonas. Physiol. Plant. 13, 726-735, 1960

10. KamiYa, N. Physical aspects of protoplasmic streaming. In The Structure of Protoplasm, ed. W. SeIfrIZ, Iowa State Univ. Press, Ames, Iowa, pp. 199-244, 1942

11. Kamiya, N., R.D. Allen, and R. Zeh. Contractile properties of the slime mold strand. Acta Protozool. 11, 113-123, 1972

12. Krzemieniewska, H. Sluzowce Polski na tle Flory Sluzowcow Europejskich, Warszawa, 1960

13. Luckens, R.J. Photo-inhibition of sporulation in Alternaria Solani. Am. J. Bot. 50, 720-724, 1962

14. NAIR, P. and G.G. ZABKA. Light quality and sporulation in myxomycetes with special reference to a red far-red reversible reaction. Mycopath. Mycol. Appl. 27, 123-128, 1965

15. Rakoczy, L. The myxomycete Physarum nudum as a model organism for photobiological studies. Ber. Deutsch. Bot. Ges. 86, 141-164, 1973

16. SchopshiRe, W. Jr. and R.B. Withrow. Action spectrum of phototropic tipcurvature of Avena. Plant Physiol. 33, 360-365, 1958

17. TAYLOR, A.O. and B.A. BonNer. Isolation of phytochrome from alga Mesotaenium and liverwort Sphaerocarpos. Plant Physiol. 42, 762-766, 1967

18. Ueda, T., K. Terayama, K. Kurihara and Y. Kobatake. Threshold phenomena in chemoreception and taxis in slime mold Physarum polycephalum. J. Gen. Physiol. 65, 223-234, 1975

19. Ueda, T., M. Muratsugu, K. Kurihara and Y. Kobatake. Chemotaxis in Physarum polycephalum: effects of chemicals on isometric tension of the plasmodial strand in relation to chemotactic movement. Exp. Cell Res., in press

20. Wegner, E.E. and A.W. Adamson. Photochemistry of complex ions. III. Absolute quantum yields for the photolysis of some aqueous chromium (III) complexes. Chemical actinometry in the long wave-length visible region. J. Am. Chem. Soc. 88, 394-404, 1966 